\title{
Differential Interactions of Falcarinol Combined with Anti-Tumour Agents on Cellular Proliferation and Apoptosis in Human Lymphoid Leukaemia Cell Lines
}

Zaini R, Haywood Small SL, Cross NA and Le Maitre CL*

Biomolecular Sciences Research Centre, Sheffield Hallam University, Sheffield, S1 1WB, UK

*Corresponding author: Christine Le Maitre, Biomolecular Sciences Research Centre, Sheffield Hallam University, Sheffield, S1 1WB, UK, Tel: 0114 225 6163; Fax: 0114225 3066; E-mail: c.lemaitre@shu.ac.uk

Received date: Feb 04, 2015, Accepted date: Mar 16, 2015, Publication date: Mar 19, 2015

Copyright: @ 2015 Zaini R, et al. This is an open-access article distributed under the terms of the Creative Commons Attribution License, which permits unrestricted use, distribution, and reproduction in any medium, provided the original author and source are credited.

\begin{abstract}
Leukaemia is the most common childhood cancer, and whilst recent advances in therapy have improved survival, current treatments are still limited by their side effects. Thus, new therapies are urgently needed, this study investigated the effects of Falcarinol, a polyacetylene isolated from carrots (Daucus carota) in combination with chemotherapy agents, anti-cancer agents and other apoptosis inducers. Inhibition of cellular proliferation and induction of apoptosis were investigated in three human lymphoid Leukaemia cell lines. Cellular proliferation was determined via ATP quantification using the Cell Titer Glo assay. Induction of apoptosis was investigated using caspase 3 activity assay and confirmed by nuclear morphology using Hoechst 33342 . The study demonstrated that CCRF-CEM cells failed to induce synergistic response with any of the investigated chemotherapies, but importantly no inhibition was observed either. Jurkat cells showed a significant synergistic induction of apoptosis following joint treatment with Falcarinol and a Death Receptor 5 agonist (DR5), whereas CCRF-CEM cells showed only an additive response. Conversely within MOLT-3 cells Falcarinol partially inhibited the induction of apoptosis by DR5 agonist although this failed to reach significance. However MOLT-3 cells demonstrated synergistic induction of apoptosis when Falcarinol was combined with either Bortezomib (proteosome inhibitor), or Sulforaphane (histone deacetylase inhibitor). Identification of interactions between natural bioactive compounds with anti-cancer drugs may provide new pathways to target cancerous cells. Furthermore, since some combinations enhance apoptosis but some inhibit apoptosis it may be important to consider these interactions for dietary advice during therapy.
\end{abstract}

Keywords: Falcarinol; Leukaemia; Apoptosis; Synergistic; Chemotherapy; Apoptotic inducers

\section{Introduction}

Leukaemia is the most common childhood cancer, whereby abnormal white blood cells (leukocytes) are produced. These abnormal cells accumulate in the bone marrow and prevent the production of other vital blood cells resulting in anaemia and immunodeficiency. Commonly, Leukaemia affects children who are between two and four years old, but children and adults of any age can develop this blood malignancy [1]. Although there are effective treatments for certain types of Leukaemia, it remains a major cause of morbidity and mortality with more than 4300 deaths from Leukaemia in the UK annually [2]. Moreover, mortality rates for both men and women from Leukaemia have shown only a very gradual decline between the late 1970's and 2008 in the UK [3], demonstrating the need to find treatments. One potential source of novel therapeutic agents is bioactive compounds isolated from natural sources. Our previous work has implicated Falcarinol a natural polyacetylene from carrots (Daucus carota) as a potential inducer of apoptosis and inhibitor of cellular proliferation within Leukaemia cell lines [4,5]. A potential role for natural agents in anti-cancer therapies is in the combination with existing chemotherapy and anti-tumour agents. If these agents interact synergistically, they could lead to a dramatic reduction in the dose of chemotherapy agents required and thus decrease side effects and the morbidity associated with their use.

Induction of apoptosis as a target for anti-cancer therapies holds great promise as apoptosis leads to the permanent removal of tumour cells without triggering an inflammatory response and causing nearby tissue damage [6]. There are two main pathways which lead to apoptosis firstly the extrinsic (death receptor) pathway where cell membrane receptors known as the death receptors (FasR, TNFR1, DR4 and DR5) are activated via cytotoxic ligands leading to caspase 8 activation, which activates the execution caspases 3, 6 and 7 [6-8]. Secondly, the intrinsic (mitochondrial) pathway is activated by induction of the pro-apoptotic members of the Bcl-2 family [8]. This induces cytochrome $c$ release and subsequent activation of caspase 9 which can then activate the effector caspases $[9,10]$. Many anti-cancer drugs induce apoptosis by the activation of both the extrinsic and intrinsic pathways [6-9,11]. For example, treatment of cancer cell lines with chemotherapy agents, such as Cisplatin, Etoposide and Methotrexate, induce activation of Fas receptors via over expression of FasL $[6,12]$. These agents can also increase production of Bax in response to DNA damage and p53 activation which leads to cytochrome $\mathrm{c}$ release from the mitochondria and activation of caspase 3 [6]. However, many agents in current use or under investigation as potential chemotherapeutic agents selectively target specific agents within apoptotic pathways. This study assesses whether selected antitumour agents act synergistically with the known pro-apoptotic and anti-proliferative effects of the natural bioactive compound: Falcarinol, in Leukaemia cell lines.

\section{Chemotherapy drugs}

Cisplatin is one of the most widely used anti-cancer drugs and is a DNA-damaging agent used in the treatment of head, neck, lung, ovarian cancers and lymphoma $[13,14]$. Nevertheless, the clinical use 
Citation: Zaini R, Small SLH, Cross NA, Le Maitre CL (2015) Differential Interactions of Falcarinol Combined with Anti-Tumour Agents on Cellular Proliferation and Apoptosis in Human Lymphoid Leukaemia Cell Lines. J Blood Disorders Transf 6: 258. doi: $10.4172 / 2155-9864.1000258$

Page 2 of 9

of Cisplatin is associated with a number of side effects including; nausea and vomiting, whilst the most serious side effects are neurotoxicity [15], and nephrotoxciity [16]. Cisplatin works by crosslinking DNA interstrand and intrastrands preventing DNA transcription, replication and cellular division (mitosis) [17,18]. The damaged DNA is then unable to undergo DNA repair and thus initiates apoptosis [18-20]. Etoposide is one of the most widely used chemotherapy agents [21-23]. Etoposide is a member of DNA topoisomerase II (topo2) inhibitors, which inhibit the ligation and joining of the DNA strands together. Thus generating DNA doublestrand breaks and induce a progressive inhibition of DNA replication $[23,24]$. Induction of DNA double-strand breaks by Etoposide has been considered as the key mechanism responsible for its proapoptotic and anti-tumour properties [24-26]. Chlorambucil is a DNA alkylating agent, which has been used as a standard chemotherapy treatment for lymphomas and CLL for more than 40 years [27]. The mechanism of action of this drug is thought to be as a result of binding to RNA, proteins and DNA. Resistance to Chlorambucil could be seen as a result of increased drug metabolism or increased DNA repair [28]. 5 -Fluorouracil (5-FU) has been widely used in the treatment of cancer over the past 30 years $[29,30]$. However, the response rates to the single-agent treatments have not been satisfactory and drug resistance remains a significant limitation to its clinical use. 5-FU induces apoptosis via induction of DNA strand breaks [31], leading to induction of $\mathrm{p} 53$, hence mutations in p53 can lead to 5-FU resistance [32].

6-Mercaptopurine (6-MP) is an immunosuppressive drug used to treat Leukaemia and lymphoma particularly childhood lymphoblastic Leukaemia (CLL) $[33,34]$. 6-MP inhibits purine nucleotide metabolism and synthesis which leads to dysfunctional synthesis and function of RNA and DNA [33]. The DNA and RNA damage that results triggers activation of intrinsic apoptosis via p53. However, because of its severe side effects including inhibition of normal haematopoiesis which can lead to increased risk of infection, anaemia and reduced blood clotting and bleeding, the use of this therapeutic strategy is problematic [33]. As such the use of dual therapies which could reduce the chemotherapy dose used, and thus lead to reduced side effects would be beneficial [35].

\section{Apoptotic inducer agents}

Bortezomib (Velcade, PS-341) is a proteasome inhibitor which induces apoptosis in several blood cancers and solid malignancies, including mantle cell lymphoma, myeloma, and $\mathrm{T}$ cell Leukaemia cell line (Jurkat) [36-40]. Combination of histone deacetylase inhibitors (HDACis) with Bortezomib within Leukaemia cell lines has demonstrated potential to overcome resistance [41,42]. However, certain natural agents have also been shown to inhibit the actions of Bortezomib, of particular note were the inhibitory actions of the dietary Flavonoid: Quercetin, in B cell lines and primary CLL cells [43]. These potential inhibitory actions highlight the importance of identifying whether natural agents act synergistically with therapeutic agents but also to ensure that they do not inhibit their actions.

Leptomycin B (LMB) is a nuclear export inhibitor, which prevents protein transfer from the nucleus to the cytoplasm through nuclear pores leading to accumulation of proteins within the nucleus such as p53 and NFKB leading to modulation of apoptotic signalling [44,45]. LMB acts synergistically with a number of anti-cancer agents such as ABL kinase inhibitor: Imatinib mesylate by excluding BCR/ABL from the cytosol leading to accumulation of death signals in the nucleus of
CML cells [46]. Sulforaphane a HDACi increases acetylated histones $\mathrm{H} 3$ and H4, leading to re-expression of silenced genes such as p21 and Bax [47]. Sulforaphane also induces apoptosis and cell cycle arrest by downregulation of NF- $\mathrm{KB}$, and inhibits cancer stem cell properties such as self-renewal and ALDH1 expression $[48,49]$.

Specific agonists to death receptors are in clinical trials and have shown promise in tumour therapies either as single agents or in combination with cytotoxic chemotherapy [50]. Mouse anti-human DR5 monoclonal antibody (AD5-10) has been shown to induce apoptosis in $\mathrm{T}$ cell Leukaemia cell line (Jurkat) [50]. However, a number of Leukaemia cell lines display partial resistance to death receptor agonists, within which, a number of Methoxyflavone derivatives have been shown to enhance death receptor induced apoptosis [51]. Here, we investigated whether Falcarinol could act synergistically with death receptor agonists to induce apoptosis.

This study tested the hypothesis that Falcarinol isolated from Daucus carota demonstrates synergistic actions on chemotherapeutic or anti-cancer agents within human lymphoid Leukaemia cell lines.

\section{Materials and Methods}

\section{Cell culture}

Three human lymphoid Leukaemia cell lines were used in this study, which we have previously shown have high sensitivity to Falcarinol [5], CCRF-CEM (acute lymphoblastic Leukaemia) (ATCC: CCL-119, Middlesex, UK); Jurkat (peripheral blood T cell Leukaemia) (ATCC: TIB-152, Middlesex, UK); and MOLT-3 (acute lymphoblastic Leukaemia patient relapsed following chemotherapy) (ATCC: CRL-1552, Middlesex, UK) [5]. All cell lines used in this study were routinely tested against mycoplasma bacterial infection using the MycoAlert $^{\circ}$ Mycoplasma Detection Kit (Lonza, USA). Cells were cultured in RPMI 1640 medium (Invitrogen, Paisley, UK) supplemented with $10 \%(\mathrm{v} / \mathrm{v})$ fetal bovine serum, $100 \mu \mathrm{g} / \mathrm{ml}$ penicillin/ streptomycin and $1.5 \mathrm{mM}$ L-Glutamine (complete RPMI) and incubated at $37^{\circ} \mathrm{C}$ with $5 \% \mathrm{CO}_{2}$. Prior to stimulation, cells number were transferred into 12 well plates at a cell density of 1 x106 cells per $\mathrm{ml}$.

\section{Individual treatment with chemotherapy agents}

Cisplatin, Chlorambucil and 5-FU were investigated at 2.5 to 10 $\mu \mathrm{M}$, whilst Etoposide was investigated at 5, 50 and $5000 \mathrm{nM}$ on CCRFCEM cells to assess their ability to inhibit ATP levels with less than $20 \%$ to be used in the combination treatment to investigate synergistic, additive or inhibitory effects.

\section{Individual treatment with anti-tumour agents}

A dose response curve for different concentrations of Falcarinol, 6MP, Bortezomib, human Death Receptor 5 (DR5) agonistic monoclonal antibody, LMB and Sulforaphane was determined using Jurkat cells. Doses which induced less than 20\% apoptotic cell death were then used in combination treatments to investigate synergistic, additive or inhibitory effects. 
Citation: Zaini R, Small SLH, Cross NA, Le Maitre CL (2015) Differential Interactions of Falcarinol Combined with Anti-Tumour Agents on Cellular Proliferation and Apoptosis in Human Lymphoid Leukaemia Cell Lines. J Blood Disorders Transf 6: 258. doi: $10.4172 / 2155-9864.1000258$

Page 3 of 9

\section{Effects of individual and combination treatment on apoptotic induction}

Half a million CCRF-CEM cells per well were treated with Cisplatin, Etoposide, Chlorambucil and 5-FU with or without Falcarinol for 24 and $48 \mathrm{~h}$. Moreover, three lymphocytic leukaemia cells; CCRF-CEM, Jurkat and MOLT-3 were treated with 6-MP, Bortezomib, DR5, LMB and Sulforaphane in the presence or absence of $6 \mu \mathrm{M}$ Falcarinol in 12 well plates, following $24 \mathrm{~h}$ cells were stained with caspase 3 activity assay (Cambridge Biosciences, Cambridge, UK) and analyzed on the flow cytometer using a BD FACS Calibur instrument (BD, Oxford, UK) as previously described. Data, from at least 10,000 events per sample, were recorded and processed using the Cell Quest software (Becton-Dickinson, UK). Dot-plots were analyzed using Flow Jo software (Tree Star, Inc). To confirm synergistic actions 200,000 cells per well were treated as above for $24 \mathrm{~h}$. Following treatments cellular content from each culture well was transferred to eppendorf tubes and centrifuged for 5 minutes at $400 \mathrm{~g}$ at $4^{\circ} \mathrm{C}$. The supernatant was removed, and cells washed in $100 \mu \mathrm{l}$ DPBS. Cells were then resuspended in $100 \mu \mathrm{l} 4 \%(\mathrm{w} / \mathrm{v})$ paraformaldhyde/DPBS and stored at $4^{\circ} \mathrm{C}$ overnight. One hundred microlitres of cell suspension was transferred to slides via 10 minute cytospin (Shandon Cytospin 3 Centrifuge) at $1000 \mathrm{rpm}$. Samples were air dried and washed twice with DPBS then stained in $100 \mu \mathrm{l}$ of $10 \mu \mathrm{g} / \mathrm{ml}$ Hoechst 33342 (Sigma, Poole, UK) for 10 minutes in the dark. Slides were mounted in $90 \%$ (v/v) glycerol/PBS and coverslips sealed with nail varnish. Nuclear morphology was examined using an Olympus BX61 fluorescence microscope using a $350 \mathrm{~nm}$ U-MNV filter (Olympus, Essex, UK). Images were captured using Q Capture- Pro 8.0 (UVP BioImaging Systems, Loughborough, UK).

\section{Effects of individual and combination treatment on proliferation}

Inhibition of cellular proliferation was assessed using Cell Titer Glo Luminescent Cell Viability Assay kit (Promega, Southampton, UK) to measure the ATP level of metabolically active cells following $24 \mathrm{~h}$ of combination treatment on CCRF-CEM, Jurkat and MOLT- 3 cell lines as per manufactures instructions.

\section{Statistical analysis}

Average and Standard error of the mean (SEM) was calculated and Stats Direct (Cheshire, UK) was used to test whether data followed a normal distribution using a Shapiro Wilke test. Data were nonparametric and thus a Kruskal-Wallis test and a Conover-Inman Post hoc test was used to investigate significant differences. Results were considered statistically significant when $\mathrm{P} \leq 0.05$. In order to investigate synergistic responses the expected additive responses from the combination treatment were calculated by adding the percentage of apoptotic cells induced from the Falcarinol treatment alone to the percentage of apoptotic cells induced by the apoptotic inducer agent under investigation. The effect was considered synergistic when the result of combination treatment was significantly higher than the expected additive effect and also to each single agent treatment, the additive response seen when the result of combination treatment was not significant to the expected additive effect, while for an inhibitory effect, the combination treatment showed a lower significant effect than the expected response.

\section{Results}

\section{Individual effects of chemotherapy agents on CCRF-CEM cells}

Cisplatin, Etoposide, Chlorambucil and 5-FU were used at different concentrations to assess their ability to induce anti-proliferative effects on CCRF-CEM cells assessed by the Cell Titer Glo assay. All concentrations of Cisplatin, Etoposide, Chlorambucil and 5Fluorouracil investigated showed a significant $(\mathrm{P} \leq 0.05)$ decrease in the percentage of ATP level following $24 \mathrm{~h}$ (data not shown). From these investigations doses of Cisplatin $(2.5 \mu \mathrm{M})$, Etoposide $(5 \mathrm{nM})$, Chlorambucil $(2.5 \mu \mathrm{M})$ and 5-Fluorouracil $(5 \mu \mathrm{M})$ were selected for further treatments as these induced less than $20 \%$ decrease in the ATP levels.

\section{Individual effects of anti-tumour agents on Jurkat cell line}

Jurkat cells were treated with different concentrations of antitumour agents individually to assess their ability to induce low levels of apoptotic cells as measured by caspase 3 activation. Treatment of Jurkat cells for $24 \mathrm{~h}$ with $6 \mu \mathrm{M}$ Falcarinol, $10 \mu \mathrm{M}$ 6-MP, $2.5 \mathrm{nM}$ Bortezomib, $25 \mathrm{ng} / \mathrm{ml}$ DR5, $0.5 \mathrm{nM}$ LMB and $25 \mu \mathrm{M}$ Sulforaphane were identified as inducing less than $20 \%$ apoptosis (Figure 1) and thus were selected for combination treatments.

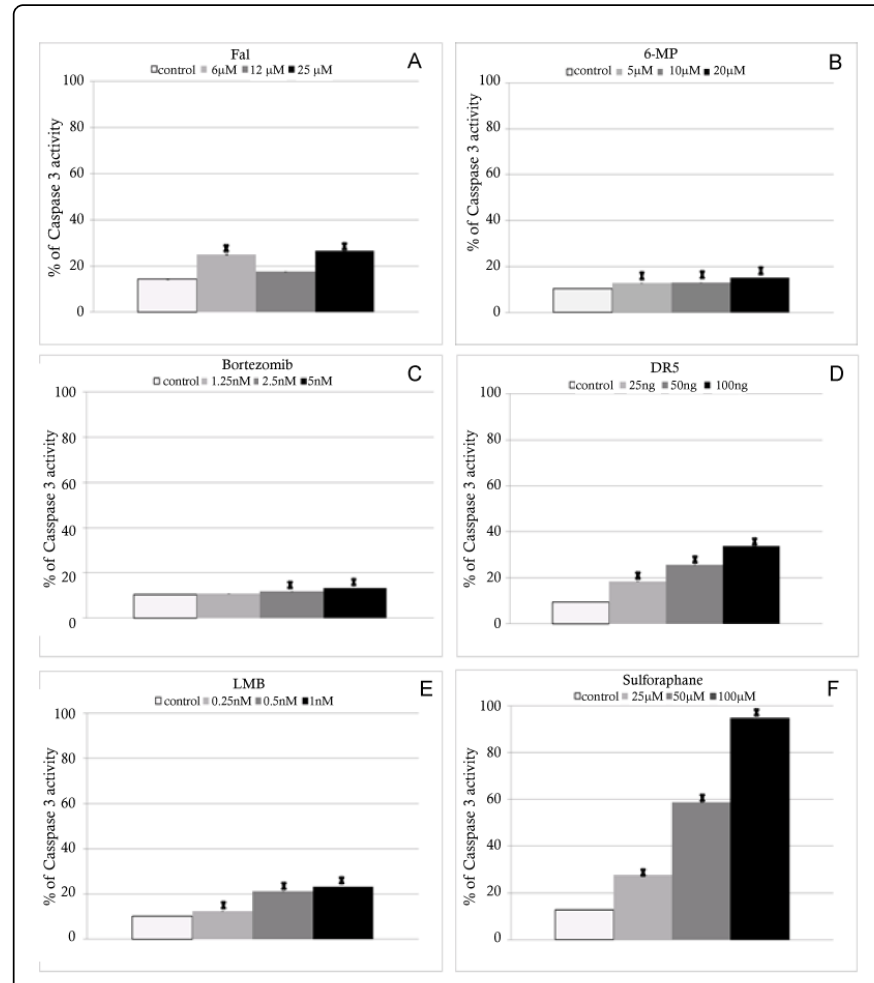

Figure 1: Induction of apoptosis detemined via caspase 3 activity assay within Jurkat cells following $24 \mathrm{~h}$ of treatment with Falcarinol (A), 6-MP (B), Bortezomib (C), DR5 agonist (D), Leptomycin B (LMB) (E) and Sulforaphane (F). Percentage cells positive for caspase 3 activitiy assay displayed as means \pm SEM, ${ }^{*} \mathrm{P}<0.05$ compared to untreated cells. 
Citation: Zaini R, Small SLH, Cross NA, Le Maitre CL (2015) Differential Interactions of Falcarinol Combined with Anti-Tumour Agents on Cellular Proliferation and Apoptosis in Human Lymphoid Leukaemia Cell Lines. J Blood Disorders Transf 6: 258. doi: $10.4172 / 2155-9864.1000258$

Page 4 of 9

\section{Combination effects on induction of apoptosis determined via caspase 3 activity and morphological analysis}

Combination therapies with chemotherapy agents: CCRF-CEM cells showed significant $(\mathrm{P} \leq 0.05)$ yet small decrease $(3 \%)$ in the number of live cells following the treatment with $5 \mu \mathrm{M}$ Falcarinol in combination with $2.5 \mu \mathrm{M}$ Cisplatin when assessed after $24 \mathrm{~h}$ (Figure $2 \mathrm{~A})$. However, the treatment with Cisplatin alone showed a greater decrease $(5.5 \%)$ in the number of live cells after $24 \mathrm{~h}$ (Figure 2A). Similarly, following $48 \mathrm{~h}$ the reduction in live cell population and increase in caspase 3 activity was significantly higher following the treatment with Cisplatin alone than in combination with Falcarinol (Figure 2A). Similarly individual Etoposide treatment showed a greater induction of apoptosis than seen following combination treatment with Falcarinol, although this was not significant to the individual treatment with Etoposide (Figure 2B). On the other hand, an additive response was seen in CCRF-CEM cells following the treatment with $5 \mu \mathrm{M}$ Falcarinol combined with $2.5 \mu \mathrm{M}$ Chlorambucil or $5 \mu \mathrm{M}$ 5-Fluorouracil following $24 \mathrm{~h}$ (Figure $2 \mathrm{C}$ and $2 \mathrm{D}$ ).
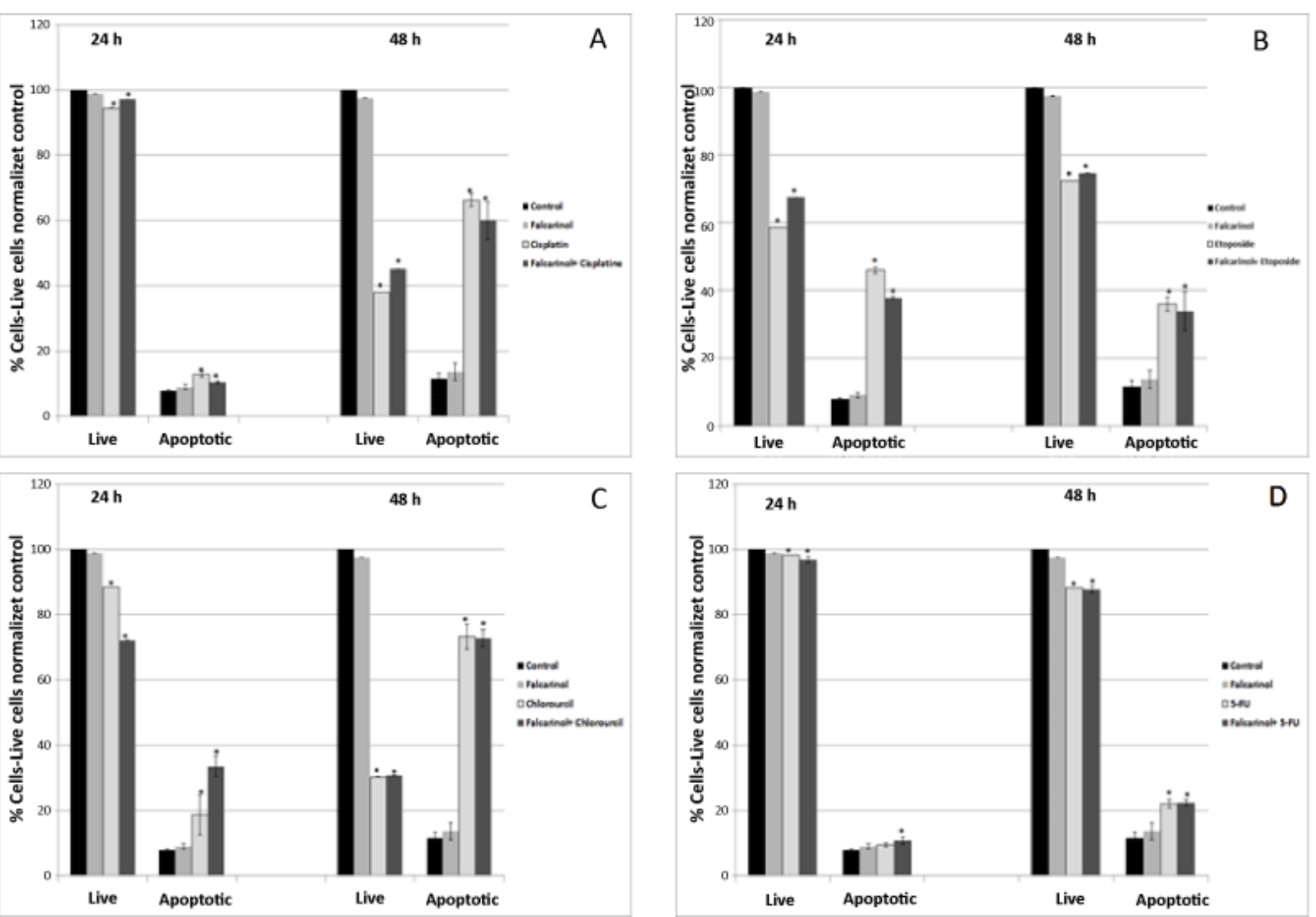

Figure 2: Induction of apoptosis detemined via caspase 3 activity assay within CCRF-CEM cell line following the treatment with Falcarinol together with Cisplatin (A), Etoposide (B), Chlorambucil (C) and 5-Fluorouracil (D) after 24 and $48 \mathrm{~h}$. Percentage cells positive for caspase 3 activitiy assay displayed as means $\pm \mathrm{SEM},{ }^{\star} \mathrm{P}<0.05$ compared to untreated cells.

All cell lines displayed an additive response when Falcarinol was combined with 6-MP (Figure 3A). MOLT-3 cells showed a significant $(\mathrm{P} \leq 0.05)$ synergistic induction of caspase 3 activity following $24 \mathrm{~h}$ incubation with Falcarinol and Bortezomib (Figure 3B). However, only an additive response was seen within CCRF-CEM and Jurkat cells (Figure 3B). These results were confirmed using morphological assessment of apoptosis (Figure 4).

CCRF-CEM cells showed no significant increase in apoptosis as determined by percentage of caspase 3 positivity with either Falcarinol or DR5 agonist alone, combination therapy was not significantly different than the expected additive effect (Figure 3C). However, Jurkat cells showed significant $(\mathrm{P} \leq 0.05)$ synergistic response following treatment with Falcarinol and DR5 agonist following $24 \mathrm{~h}$ (Figure 3C).
Morphological assessment confirmed these results (Figure 5). In contrast, an inhibitory effect was observed following the treatment with Falcarinol combined with DR5 agonist in MOLT-3 cells compared to single agent treatments (Figure 3C).

However, no synergistic response were seen following combination of Falcarinol with Leptomycin B (Figure 3D). MOLT-3 cells showed a significant $(P \leq 0.05)$ synergistic induction of caspase 3 activity following $24 \mathrm{~h}$ incubation with Falcarinol and Sulforaphane (Figure 3E). Conversely CCRF-CEM and Jurkat cells only demonstrated additive responses when Falcarinol was combined with Sulforaphane (Figure 3E). 
Citation: Zaini R, Small SLH, Cross NA, Le Maitre CL (2015) Differential Interactions of Falcarinol Combined with Anti-Tumour Agents on Cellular Proliferation and Apoptosis in Human Lymphoid Leukaemia Cell Lines. J Blood Disorders Transf 6: 258. doi: $10.4172 / 2155-9864.1000258$

Page 5 of 9

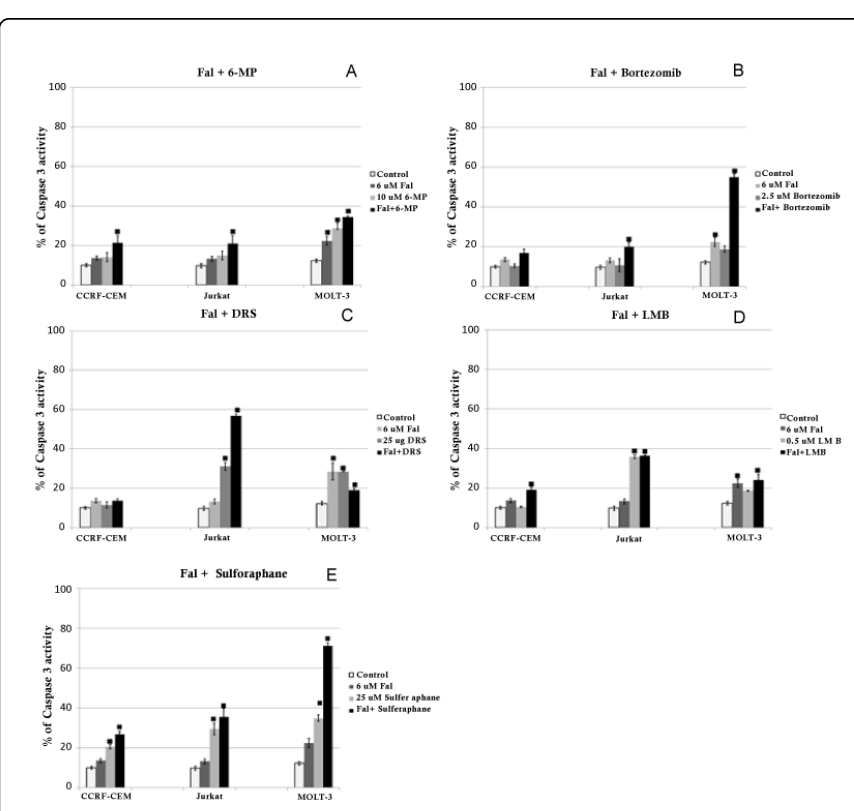

Figure 3: Induction of apoptosis detemined via caspase 3 activity assay within CCRF-CEM, Jurkat and MOLT-3 cells following combination treatments with Falcarinol together with 6mercaptopurine (A), Bortezomib (B), DR5 agonist (C), Leptomycin B (D) and Sulforaphane (E) after $24 \mathrm{~h}$. Percentage cells positive for caspase 3 activitiy assay displayed as means \pm SEM, ${ }^{*} \mathrm{P}<0.05$ compared to untreated cells.
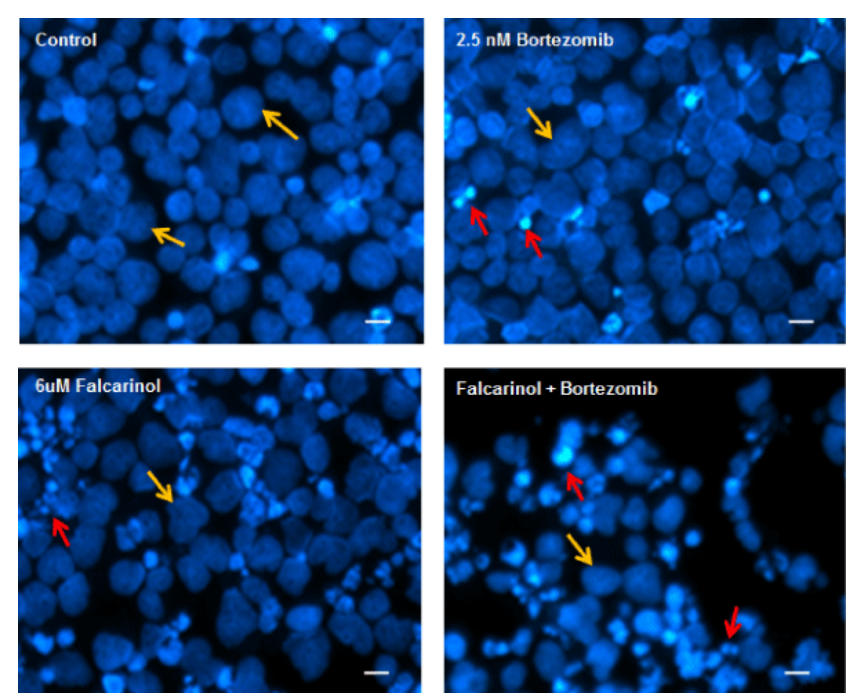

Figure 4: Induction of apoptosis determined via nuclear morphology following Hoechst 33342 stain following treatment of MOLT 3 cells for $24 \mathrm{~h}$ with Falcarinol and Bortezomib alone and in combination. Scale bar $=25 \mu \mathrm{m}$.
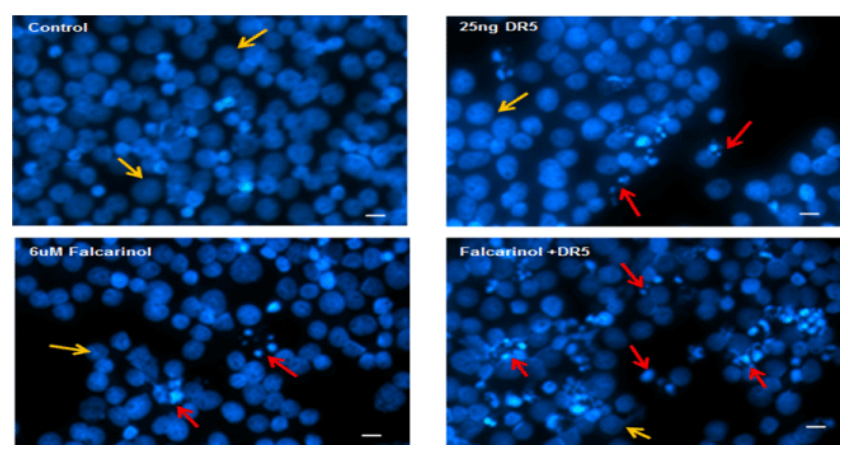

Figure 5: Induction of apoptosis determined via nuclear morphology following Hoechst 33342 stain following treatment of Jurkat cells for $24 \mathrm{~h}$ with $25 \mathrm{ng} / \mathrm{ml}$ DR5 and $6 \mu \mathrm{M}$ Falcarinol, as either single agents or in combination. Scale bar $=25 \mu \mathrm{m}$.

\section{Combination effects on cellular viability determined via ATP levels}

6-MP demonstrated a direct inhibitory effect on ATP production when assessed with Cell Titer Glo (Figure 6A). This was also confirmed with Trypan blue staining assay to determine the level of live cells, which showed a significant $(\mathrm{P} \leq 0.05)$ decrease in the number of viable cells after treatment with Falcarinol alone and 6-MP alone and significant increase $(\mathrm{P} \leq 0.05)$ following combination treatment.

CCRF-CEM, Jurkat and MOLT-3 cells showed a significant decrease in ATP level compared to control cells following combined treatment with Falcarinol and Bortezomib for $24 \mathrm{~h}(\mathrm{P} \leq 0.05)$ (Figure $6 \mathrm{~B})$.

Single and combination treatment with Falcarinol alone and Falcarinol with DR5 agonist showed no significant decrease in ATP levels in CCRF-CEM. However, Jurkat cell line showed a significant decrease in the level of metabolically active cells after combination treatments compared to the treatment with either DR5 agonist or Falcarinol alone (Figure 6C). Moreover, MOLT-3 cells showed a 35\% decrease with Falcarinol, no effect with DR5 and only $17 \%$ decrease in ATP levels with combination treatment (Figure 6C).

All three Leukaemia cell lines showed a significant decrease in ATP level when assessed after $24 \mathrm{~h}$ treatment with Falcarinol in combination with Leptomycin B (Figure 6D). Similarly, the effect of Falcarinol and Sulforaphane treatment on all examined cells significantly decreased ATP levels $(\mathrm{P} \leq 0.05)$.

For example, in CCRF-CEM the ATP level decreased $25 \%$ in cells treated individually with Falcarinol or Sulforaphane whereas the combined treatment showed approximately $40 \%$ reduction in ATP levels (Figure 6E). 
Citation: Zaini R, Small SLH, Cross NA, Le Maitre CL (2015) Differential Interactions of Falcarinol Combined with Anti-Tumour Agents on Cellular Proliferation and Apoptosis in Human Lymphoid Leukaemia Cell Lines. J Blood Disorders Transf 6: 258. doi: $10.4172 / 2155-9864.1000258$

Page 6 of 9

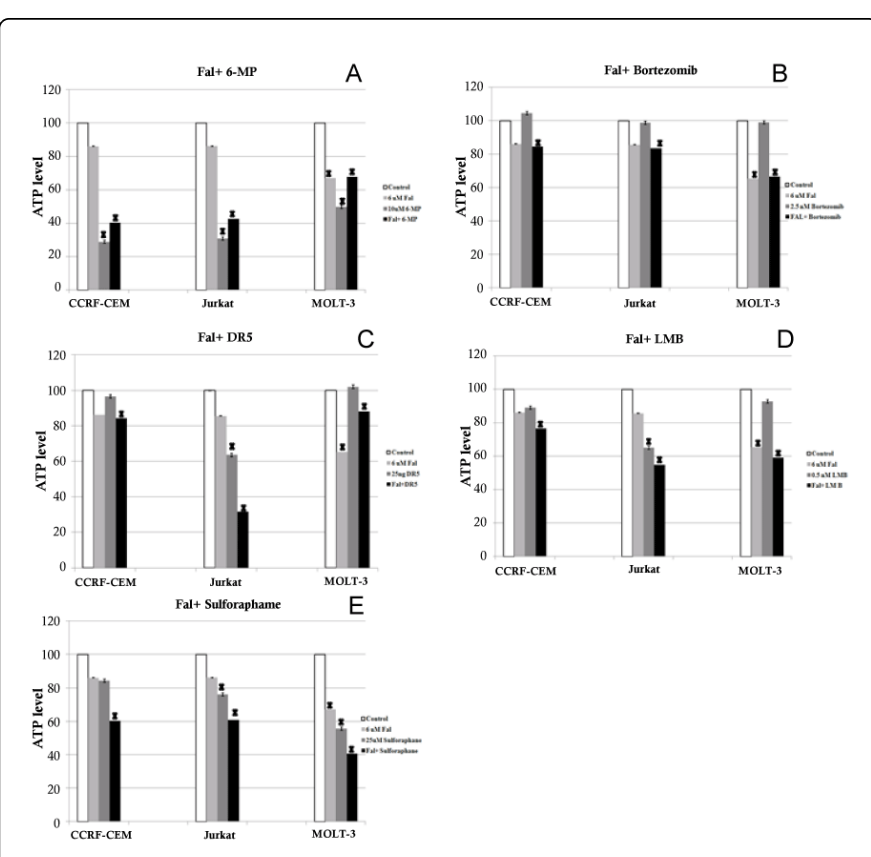

Figure 6: Cellular viability investigated using Cell Titre Glo assay to measure the ATP levels as a measure of cell viability within three human Leukaemia cell lines (CCRF-CEM, Jurkat and MOLT-3) following $24 \mathrm{~h}$ of individual and combied treatment with Falcarinol, DR5, Bortezomib, Leptomycin B, Sulforaphane and 6MP. Percentage ATP levels normalized to untreated controls displayed as means $\pm \mathrm{SEM},{ }^{*} \mathrm{P}<0.05$ compared to untreated cells.

\section{Discussion}

Falcarinol, a natural polyacetylene from carrots (Daucus carota) has been previously indicated as an inducer of apoptosis and inhibitor of cellular proliferation within Leukaemia cell lines $[4,5]$. The key potential for natural agents in anti-cancer therapies is in the combination with existing chemotherapy and anti-tumour agents. If chemotherapy and anti-tumour agents interact synergistically with Falcarinol, this could lead to a dramatic reduction in the dose of chemotherapy agents required and thus decrease side effects and the associated morbidity with their use. Here, we demonstrated that the combination of Falcarinol with several apoptotic inducer agents or chemotherapy drugs resulted in differential responses within three human lymphoid Leukaemia cell lines.

CCRF-CEM cells failed to show any synergistic response with either of the investigated chemotherapies (Cisplatin, Etoposide, Chlorambucil and 5-Fluorouracil). Cisplatin treatment in CCRF-CEM cells in combination with Falcarinol showed a lower cytotoxic effect toward live cells as well as apoptotic induction when compared to the individual treatment with $2.5 \mu \mathrm{M}$ Cisplatin following 24 and $48 \mathrm{~h}$. Similarly, apoptotic induction within CCRF-CEM cells was greater following $24 \mathrm{~h}$ treatment with Etoposide alone, than in combination with Falcarinol. However, an additive response in CCRF-CEM was seen when treated with Falcarinol combined with Chlorambucil or 5Fluorouracil following $24 \mathrm{~h}$. Similar to our results, Kwa and colleagues (2010) found that the treatment with Chlorambucil with the HDACi, sodium butyrate resulted in an additive induction of apoptosis within lymphoid leukaemia cell lines LP-1 after 3 days post treatment [52]. In addition, treatment with 5-Fluorouracil in combination with fish oilbased lipid emulsion (FO) which was rich in omega-3 fatty acids showed a greater effect on growth inhibition of the colon cancer cell line Caco-2 than 5-FU alone [53].

6-MP demonstrated additive actions with Falcarinol, inducing caspase- 3 activity within all three Leukaemia cell lines. In contrast, the ATP level of combined treatment was significantly higher than single agent treatment, this suggests that the combination of 6-MP with Falcarinol results in a reduced effectiveness of 6-MP.

Within CCRF-CEM and Jurkat cells, no significant increase in caspase-3 activity was observed either with individual or combined treatment with Falcarinol and Bortezomib after $24 \mathrm{~h}$ although increases were observed which did not reach significance. MOLT-3 cells showed a significant synergistic response to Falcarinol and Bortezomib treatment with $15 \%$ higher apoptotic cells compared to the expected additive effect, in contrast the ATP level of metabolically active cells showed similar decreases following Falcarinol alone and in combination with Bortezomib (67\%), demonstrating a specific synergistic response to induction of apoptosis as opposed to cellular proliferation which warrants further investigation. The targeted synergy to apoptosis suggests increased sensitivity to unfolded proteins or accelerated accumulation of proteasome degraded proapoptotic factors such as the FOXO transcription factors.

Jurkat cells demonstrated sensitivity to DR5 agonists, inducing apoptosis and inhibiting cellular proliferation which agrees with previous studies [50]. A number of agents have been shown to act as sensitizers to DR5 ligands, including TRAIL [54], here we demonstrated Falcarinol induced apoptosis in a synergistic manner with DR5 agonists suggesting its role as a TRAIL sensitizer. Here, we show for the first time that MOLT-3 cells are sensitive to DR5 agonists, which has been shown previously for MOLT-4 cells [55] which are derived from the same patient. Importantly however within these cells an antagonistic effect was seen in combination with Falcarinol. The differential effects seen between cell lines highlights key differences in apoptotic signalling between leukaemia cell lines [56]. Jurkat cells which have been shown to be highly sensitive to DR5 agonists previously [57], classically undergo type I rapid apoptosis and a synergistic induction of apoptosis was observed in these cells when combined with Falcarinol. In contrast, most tumour cell lines undergo type II apoptosis, which could account for differential affects between Jurkat and MOLT-3 cells. Interestingly other agents which synergistically induce apoptosis in leukaemia cells have been shown to act via increasing the expression of DR5 but not DR4 via activation of JNK signalling [58], further studies are required to determine if this is the mechanism of synergy induced by Falcarinol.

In this study, we demonstrated that Leptomycin B (LMB) significantly induced apoptosis and decreased proliferation in all cell lines, although synergistic interactions were not observed additive responses were seen. Leptomycin B is known to induce apoptosis through blocking CRM-1 mediated nuclear exports leading to accumulation of pro-apoptotic proteins such as p53, FOXO transcription factors and HSP 27 within the nucleus [44,59]. In 2006, a study showed synergistic actions of Leptomycin B with the ABL kinase inhibitor Imatinib Mesylate [46]. These actions are thought to be brought about by Leptomycin $\mathrm{B}$ trapping $\mathrm{BCR} / \mathrm{ABL}$ in the nucleus and thus BCR/ABL cannot induce proliferation/survival as this signal is normally passed on to cytoplasmic mediators [46]. Nuclear accumulation of p53, FOXO transcription factors and HSP 27 within 
Citation: Zaini R, Small SLH, Cross NA, Le Maitre CL (2015) Differential Interactions of Falcarinol Combined with Anti-Tumour Agents on Cellular Proliferation and Apoptosis in Human Lymphoid Leukaemia Cell Lines. J Blood Disorders Transf 6: 258. doi: $10.4172 / 2155-9864.1000258$

Page 7 of 9

the nucleus may induce apoptosis, however the lack of synergy observed within the current study with Leptomycin suggests that Falcarinol induced apoptosis is unlikely to be via increased signalling through CRM-1 responsive pro apoptotic transcription factors such as FOXO.

Combination treatment with Falcarinol and the HDACi, Sulforaphane showed only an additive response in CCRF-CEM and Jurkat cells after $24 \mathrm{~h}$ whereas a significant synergistic effect was observed in MOLT- 3 cells as determined by caspase- 3 activity and nuclear morphology. Sulforaphane has been previously demonstrated to induce apoptosis within U937 cells and Jurkat cells [60,61]. Moreover, Sulforaphane significantly inhibited cellular growth within CCRF-CEM and Jurkat cells following combined treatment with Falcarinol. HDACi inhibit proliferation and induce apoptosis via reexpression of tumour suppressor genes, such as p21 that have been epigenetically silenced by chromatin modifications [60]. HDACi prevents histone deacetylation and since acetylated chromatin is more transcriptionally active it is associated with tumour suppressor gene re-expression. Thus the synergistic responses seen within MOLT-3 highlight the potential role of Falcarinol in modulating tumour suppressor gene expression, or their downstream pro-apoptotic actions.

For the first time this study has shown that combination treatments with the bioactive compound: Falcarinol, isolated from Daucus carota together with a number of classical inducers of apoptosis and chemotherapy agents, could act in a synergistic, additive or inhibitory manner dependent on cell line and combination treatments. Interestingly the related aliphatic C17Polyactelene Panaxynol [62], isolated from Panax notoginseng has also been shown to induce apoptosis in the leukaemia cell line HL-60 via activation of PKC $\delta$, caspase 3 activation and cleavage of poly(ADP[adenosine diphosphate]-ribose) polymerase (PARP) [63]. Here we also show Falcarinol results in activation of caspase 3 and induction of apoptosis. However to date, the direct actions of polyacetylenes in the induction of apoptosis have not been elucidated, many studies demonstrate induction of classical pathways involved in apoptosis, however these do not indicate whether these are the primary targets for polyacetylenes or merely products of the apoptotic cascade. The synergistic responses observed following combination of Falcarinol with classical apoptosis inducers seen here, highlight differential mechanism of apoptosis in leuakemia cell lines. CCRF-CEM, the most sensitive cell line to Falcarinol, failed to demonstrate any synergistic responses when combined with apoptotic inducers. Jurkat cells treated with Falcarinol and DR5 agonist showed synergistic induction of apoptosis suggesting Falcarinol may increase expression of DR5 within Jurkat cells but not CCRF-CEM and MOLT-3 cells. However as Jurkat cells are known to undergo type I apoptosis unlike most tumour cells, Falcarinol may be increasing DR5 activation via the caspase 8 activation of caspase 3 whilst not affecting the intrinsic (mitochondrial pathways), hence the lack of response seen in CCRF-CEM and MOLT 3 cells [64]. Whilst synergistic induction of apoptosis was observed in MOLT-3 cells when Falcarinol was combined with proteosome inhibitors and HDACi, suggesting direct actions on proteins involved in apoptotic signaling. Thus highlighting the need for further investigation into the mechanisms of apoptotic induction by Falcarinol alone and in combination across a spectrum of leukaemia cell lines and primary leukaemia cells.

The combined effect of Falcarinol on induction of cell death and inhibition of cellular proliferation indicate that this agent could be beneficial in improving Leukaemia therapy, however combination therapies could also prevent the actions of some anti-tumour agents. Identification of interactions between natural bioactive compounds with anti-cancer drugs may provide new pathways to target cancerous cells. Furthermore, since some combinations enhance apoptosis but some inhibit apoptosis it may be important to consider these interactions for dietary advice during therapy.

\section{Funding}

This study is funded by the Saudi Ministry of Health.

\section{Acknowledgements}

The Authors would like to thank Dr Kerstin Brandt, Newcastle University, Newcastle, NE1 7RU, UK for supply of the Falcarinol.

\section{References}

1. https://leukaemialymphomaresearch.org.uk/patient-information/ leukaemia.

2. http://www.cancerresearchuk.org/cancer-info/cancerstats/type/ Leukaemia/a=5441.

3. http://www.cancerresearchuk.org/cancer-info/cancerstats/types/ leukaemia/mortality/.

4. Zaini RG, Brandt K, Clench MR, Le Maitre CL (2012) Effects of bioactive compounds from carrots (Daucus carota L.), polyacetylenes, betacarotene and lutein on human lymphoid leukaemia cells. Anticancer Agents Med Chem 12: 640-652.

5. Zaini R, Clench MR, Le Maitre CL (2011) Bioactive chemicals from carrot (Daucus carota) juice extracts for the treatment of leukemia. J Med Food 14: 1303-1312.

6. Vermeulen K, Van Bockstaele DR, Berneman ZN (2005) Apoptosis: mechanisms and relevance in cancer. Ann Hematol 84: 627-639.

7. Brady HJ (2003) Apoptosis and leukaemia. Br J Haematol 123: 577-585.

8. Marsden VS, Strasser A (2003) Control of apoptosis in the immune system: Bcl-2, BH3-only proteins and more. Annu Rev Immunol 21: 71-105.

9. Adams JM (2003) Ways of dying: multiple pathways to apoptosis. Genes Dev 17: 2481-2495.

10. Rastogi RP, Sinha R, Sinha RP (2010) Apoptosis: Molecular mechanisms and pathogenicity. EXCLI Journal 8:155-181.

11. Fadeel B, Orrenius S (2005) Apoptosis: a basic biological phenomenon with wide-ranging implications in human disease. J Intern Med 258: 479-517.

12. Müller M, Strand S, Hug H, Heinemann EM, Walczak H, et al. (1997) Drug-induced apoptosis in hepatoma cells is mediated by the CD95 (APO-1/Fas) receptor/ligand system and involves activation of wild-type p53. J Clin Invest 99: 403-413.

13. Zamble DB, Lippard SJ (1995) Cisplatin and DNA repair in cancer chemotherapy. Trends Biochem Sci 20: 435-439.

14. Cilenti L, Kyriazis GA, Soundarapandian MM, Stratico V, Yerkes A, et al. (2005) Omi/HtrA2 protease mediates cisplatin-induced cell death in renal cells. Am J Physiol Renal Physiol 288: F371-379.

15. Harmers FP, Gispen WH, Neijt JP (1991) Neurotoxic side-effects of cisplatin. Eur J Cancer 27: 372-376.

16. Abdel Moneim AE, Othman MS, Aref AM (2014) Azadirachta indica attenuates cisplatin-induced nephrotoxicity and oxidative stress. Biomed Res Int 2014: 647131.

17. Perez RP (1998) Cellular and molecular determinants of cisplatin resistance. Eur J Cancer 34: 1535-1542.

18. Gonzalez VM, Fuertes MA, Alonso C, Perez JM (2001) Is cisplatininduced cell death always produced by apoptosis? Mol Pharmacol 59: 657-663. 
Citation: Zaini R, Small SLH, Cross NA, Le Maitre CL (2015) Differential Interactions of Falcarinol Combined with Anti-Tumour Agents on Cellular Proliferation and Apoptosis in Human Lymphoid Leukaemia Cell Lines. J Blood Disorders Transf 6: 258. doi: $10.4172 / 2155-9864.1000258$

Page 8 of 9

19. Pinto AL, Lippard SJ (1985) Binding of the antitumor drug cisdiamminedichloroplatinum(II) (cisplatin) to DNA. Biochim Biophys Acta 780: 167-180.

20. Chupin V, de Kroon AI, de Kruijff B (2004) Molecular architecture of nanocapsules, bilayer-enclosed solid particles of Cisplatin. J Am Chem Soc 126: 13816-13821.

21. Hainsworth JD, Johnson DH, Frazier SR, Greco FA (1990) Chronic daily administration of oral etoposide in refractory lymphoma. Eur J Cancer 26: 818-821.

22. Mascaux C1, Paesmans M, Berghmans T, Branle F, Lafitte JJ, et al. (2000) A systematic review of the role of etoposide and cisplatin in the chemotherapy of small cell lung cancer with methodology assessment and meta-analysis. Lung Cancer 30: 23-36.

23. Montecucco A, Biamonti G (2007) Cellular response to etoposide treatment. Cancer Lett 252: 9-18.

24. Tanaka T, Halicka HD, Traganos F, Seiter K, Darzynkiewicz Z (2007) Induction of ATM activation, histone $\mathrm{H} 2 \mathrm{AX}$ phosphorylation and apoptosis by etoposide: relation to cell cycle phase. Cell Cycle 6: 371-376.

25. Baldwin EL, Osheroff N (2005) Etoposide, topoisomerase II and cancer. Curr Med Chem Anticancer Agents 5: 363-372.

26. Hanna N, Neubauer M, Yiannoutsos C, McGarry R, Arseneau J, et al. (2008) Phase III study of cisplatin, etoposide, and concurrent chest radiation with or without consolidation docetaxel in patients with inoperable stage III non-small-cell lung cancer: the Hoosier Oncology Group and U.S. Oncology. J Clin Oncol 26: 5755-5760.

27. Rai KR, Peterson BL, Appelbaum FR, Kolitz J, Elias L, et al. (2000) Fludarabine compared with chlorambucil as primary therapy for chronic lymphocytic leukemia. N Engl J Med 343: 1750-1757.

28. Begleiter A, Mowat M, Israels LG, Johnston JB (1996) Chlorambucil in chronic lymphocytic leukemia: mechanism of action. Leuk Lymphoma 23: $187-201$.

29. Sampath D, Rao VA, Plunkett W (2003) Mechanisms of apoptosis induction by nucleoside analogs. Oncogene 22: 9063-9074.

30. Yang L, Wu D, Luo K, Wu S, Wu P (2006) Andrographolide enhances 5fluorouracil-induced apoptosis via caspase-8-dependent mitochondrial pathway involving p53 participation in hepatocellular carcinoma (SMMC-7721) cells. Cancer Lett 276: 180 .

31. Zhang N, Yin Y, Xu SJ, Chen WS (2008) 5-Fluorouracil: mechanisms of resistance and reversal strategies. Molecules 13: 1551-1569.

32. Ceilley RI (2012) Mechanisms of action of topical 5-fluorouracil: review and implications for the treatment of dermatological disorders. J Dermatolog Treat 23: 83-89.

33. Podsiadlo P, Sinani VA, Bahng JH, Kam NW, Lee J, et al. (2008) Gold nanoparticles enhance the anti-leukemia action of a 6-mercaptopurine chemotherapeutic agent. Langmuir 24: 568-574.

34. Relling MV, Hancock ML, Boyett JM, Pui CH, Evans WE (1999) Prognostic importance of 6-mercaptopurine dose intensity in acute lymphoblastic leukemia. Blood 93: 2817-2823.

35. Kano Y, Akutsu M, Suzuki K, Yoshida M (1993) Effects of carboplatin in combination with other anticancer agents on human leukemia cell lines. Leuk Res 17: 113-119.

36. Pham LV, Tamayo AT, Yoshimura LC, Lo P, Ford RJ (2003) Inhibition of constitutive NF-kappa B activation in mantle cell lymphoma B cells leads to induction of cell cycle arrest and apoptosis. J Immunol 171: 88-95.

37. Hideshima T, Richardson P, Chauhan D, Palombella VJ, Elliott PJ, et al. (2001) The proteasome inhibitor PS-341 inhibits growth, induces apoptosis, and overcomes drug resistance in human multiple myeloma cells. Cancer Res 61: 3071-3076.

38. Griger Z, Tóth BI, Baráth S, Gyetvai A, Kovács I, et al. (2011) Different effects of Bortezomib on the expressions of various PKC isoenzymes in T cells of patients with systemic lupus erythematosus and in Jurkat cells. Scand J Immunol .

39. Chen JF, Jin J (2009) [Apoptosis in Jurkat cells induced by bortezomib combined with adriamycin]. Zhonghua Zhong Liu Za Zhi 31: 890-893.
40. An J, Sun Y, Fisher M, Rettig MB (2004) Antitumor effects of bortezomib (PS-341) on primary effusion lymphomas. Leukemia 18: 1699-1704.

41. Nie D, Huang K, Yin S, Li Y, Xie S, et al. (2012) Synergistic/additive interaction of valproic acid with bortezomib on proliferation and apoptosis of acute myeloid leukemia cells. Leuk Lymphoma 53: 2487-2495.

42. Dai Y, Chen S, Wang L, Pei XY, Kramer LB, et al. (2011) Bortezomib interacts synergistically with belinostat in human acute myeloid leukaemia and acute lymphoblastic leukaemia cells in association with perturbations in NF-Î०B and Bim. Br J Haematol 153: 222-235.

43. Liu FT, Agrawal SG, Movasaghi Z, Wyatt PB, Rehman IU, et al. (2008) Dietary flavonoids inhibit the anticancer effects of the proteasome inhibitor bortezomib. Blood 112: 3835-3846.

44. Hoshino I, Matsubara H, Komatsu A, Akutsu Y, Nishimori T, et al. (2008) Combined effects of p53 gene therapy and leptomycin B in human esophageal squamous cell carcinoma. Oncology 75: 113-119.

45. Jang BC, Paik JH, Jeong HY, Oh HJ, Park JW, et al. (2004) Leptomycin Binduced apoptosis is mediated through caspase activation and downregulation of Mcl-1 and XIAP expression, but not through the generation of ROS in U937 leukemia cells. Biochem Pharmacol 68: 263-274.

46. Aloisi A, Di Gregorio S, Stagno F, Guglielmo P, Mannino F, et al. (2006) BCR-ABL nuclear entrapment kills human CML cells: ex vivo study on 35 patients with the combination of imatinib mesylate and leptomycin B. Blood 107: 1591-1598.

47. Myzak MC, Dashwood WM, Orner GA, Ho E, Dashwood RH (2006) Sulforaphane inhibits histone deacetylase in vivo and suppresses tumorigenesis in Apc-minus mice. FASEB J 20: 506-508.

48. Kallifatidis G, Rausch V, Baumann B, Apel A, Beckermann BM, et al. (2009) Sulforaphane targets pancreatic tumour-initiating cells by NFkappaB-induced antiapoptotic signalling. Gut 58: 949-963.

49. Rausch V, Liu L, Kallifatidis G, Baumann B, Mattern J, et al. (2010) Synergistic activity of sorafenib and sulforaphane abolishes pancreatic cancer stem cell characteristics. Cancer Res 70: 5004-5013.

50. Guo Y, Chen C, Zheng Y, Zhang J, Tao X, et al. (2005) A novel antihuman DR5 monoclonal antibody with tumoricidal activity induces caspase-dependent and caspase-independent cell death. J Biol Chem 280: 41940-41952.

51. Wudtiwai B, Sripanidkulchai B, Kongtawelert P, Banjerdpongchai R (2011) Methoxyflavone derivatives modulate the effect of TRAILinduced apoptosis in human leukemic cell lines. J Hematol Oncol 4: 52.

52. Kwa FA, Cole-Sinclair M, Kapuscinski M (2010) Chlorambucil-sensitive and-resistant lymphoid cells display different responses to the histone deacetylase inhibitor, sodium butyrate. Biochem Biophys Res Commun; 403: 288-292.

53. Jordan A, Stein J (2003) Effect of an omega-3 fatty acid containing lipid emulsion alone and in combination with 5-fluorouracil (5-FU) on growth of the colon cancer cell line Caco-2. Eur J Nutr 42: 324-331.

54. Mahalingam D, Szegezdi E, Keane M, de Jong S, Samali A (2009) TRAIL receptor signalling and modulation: Are we on the right TRAIL? Cancer Treat Rev 35: 280-288.

55. Wang J, Lin Z, Qiao CX, Lv M, Yu M, et al. (2008) Characterization of a novel anti-DR5 monoclonal antibody WD1 with the potential to induce tumor cell apoptosis. Cell Mol Immunol 5: 55-60.

56. Almasan A, Ashkenazi A (2003) Apo2L/TRAIL: apoptosis signaling, biology, and potential for cancer therapy. Cytokine Growth Factor Rev 14: $337-348$

57. Du YW, Chen JG, Bai HL, Huang HY, Wnag J, et al. (2011) A Novel agonistic anti-human death receptor 5 monoclonal antibody with tumoricidal acticity induces caspase and mitochondrial dependant apoptosis in human leukemia Jurkat cells. Cancer Biother Radiopharm 26: 143-152.

58. Chen D, Chan R, Waxman S, Jing Y (2006) Buthionine Sulfoximine enhancement of arsenic trioxide-induced apoptosis in leukemia and lymphoma cells is mediated via activation of c-Jun NH2 terminal Kinase and Up regulation of death receptors. Cancer Res 66: 11416-11423. 
Citation: Zaini R, Small SLH, Cross NA, Le Maitre CL (2015) Differential Interactions of Falcarinol Combined with Anti-Tumour Agents on Cellular Proliferation and Apoptosis in Human Lymphoid Leukaemia Cell Lines. J Blood Disorders Transf 6: 258. doi: $10.4172 / 2155-9864.1000258$

Page 9 of 9

59. Jang BC, Muñoz-Najar U, Paik JH, Claffey K, Yoshida M, et al. (2003) Leptomycin B, an inhibitor of the nuclear export receptor CRM1, inhibits COX-2 expression. J Biol Chem 278: 2773-2776.

60. Choi WY, Choi BT, Lee WH, Choi YH (2008) Sulforaphane generates reactive oxygen species leading to mitochondrial perturbation for apoptosis in human leukemia U937 cells. Biomedicine \& Pharmacotherapy 62: 637-644.

61. Fimognari C, Lenzi M, Sciuscio D, Cantelli-Forti G, Hrelia P (2007) Cellcycle specificity of sulforaphane-mediated apoptosis in Jurkat T-leukemia cells. In Vivo 21: 377-380.
62. Purup S, Larsen E, Christensen LP (2009) Differential effects of falcarinol and related aliphatic $\mathrm{C}(17)$-polyacetylenes on intestinal cell proliferation. J Agric Food Chem 57: 8290-8296.

63. Yan Z, Yang R, Jiang Y, Yang Z, Yang J, et al. (2011) Induction of apoptosis in human promyelocytic leukemia HL60 cells by panaxynol and panaxydol. Molecules 16: 5561-5573.

64. Shawgo ME, Shelton SN, Robertson JD (2009) Caspase-9 activation by the apoptosome is not required for fas-mediated apoptosis in type II Jurkat cells. J Biol Chem 284: 33447-33455. 